\title{
Deafness-enamel hypoplasia-nail defects syndrome
}

INSERM

\section{Source}

INSERM. (1999). Orphanet: an online rare disease and orphan drug data base. Deafnessenamel hypoplasia-nail defects syndrome. ORPHA:3220

Deafness-enamel hypoplasia-nail defects syndrome is characterised by sensorineural hearing loss, generalised enamel hypoplasia of the permanent dentition with normal primary dentition, and nail defects (Beau's lines and leukonychia). Less than 10 patients have been described so far. Transmission is autosomal recessive. 